\begin{tabular}{|c|l|}
\hline Title & Composition and electronic properties of electrochemically deposited CdT e films \\
\hline Author(s) & Takahashi, Makoto; U osaki, Kohei; Kita, Hideaki \\
\hline Citation & $\begin{array}{l}\text { Journal of A pplied Physics, 55(10), 3879-3881 } \\
\text { https://doi.org/10.1063/1.332904 }\end{array}$ \\
\hline Issue Date & 1984 05-15 \\
\hline Doc URL & http://hdl.handle.net/2115/6126 \\
\hline Rights & Copyright $\odot$ 1984 A merican Institute of Physics \\
\hline Type & article \\
\hline File Information & JAP55-10.pdf \\
\hline
\end{tabular}

Instructions for use 


\title{
Composition and electronic properties of electrochemically deposited CdTe films
}

\author{
Makoto Takahashi, Kohei Uosaki, a) and Hideaki Kita \\ Department of Chemistry, Faculty of Science, Hokkaido University, Sapporo 060, Japan
}

(Received 21 November 1983; accepted for publication 17 January 1984)

\begin{abstract}
The composition, type of semiconductivity, and resistivity of CdTe films deposited electrochemically from an aqueous solution of $\mathrm{pH}=1.4$ containing $1 \mathrm{M} \mathrm{CdSO}_{4}$ and $1 \mathrm{mM} \mathrm{TeO}_{2}$ were investigated. $\mathrm{X}$-ray diffraction peaks confirmed the formation of $\mathrm{CdTe}$ in the films deposited at potentials between -0.20 and $-0.65 \mathrm{~V}$ (vs Ag/AgCl). The films deposited at potentials more positive than $-0.35 \mathrm{~V}$ contained free $\mathrm{Te}$ in addition to $\mathrm{CdTe}$. X-ray measurements showed that the more positive the deposition potential, the higher the concentration of free $\mathrm{Te}$ in the film.

Auger electron spectroscopy measurements also confirmed that the $\mathrm{Te} / \mathrm{Cd}$ ratio was higher in the films deposited at more positive potentials. The films deposited at potentials more positive than $-0.35 \mathrm{~V}$ were $p$ type and those deposited at more negative potentials were $n$ type. The relation between the deposition potential and sheet resistance was "volcano" like and it seemed that the films deposited around $-0.35 \mathrm{~V}$ where the semiconductivity of the films changed showed maximum resistivity.
\end{abstract}

PACS numbers: 73.60.Fw, 68.60. $+\mathrm{q}, 81.15 . \mathrm{Lm}$

Cadmium telluride ( $\mathrm{CdTe}$ ) is one of the most attractive semiconductors for use in photovoltaics and photoelectrochemical cells because of its optimum energy gap $(E g=1.44$ $\mathrm{eV})^{1}$ and the availability of $p$ - and $n$-type materials. ${ }^{2}$ The electrochemical deposition may offer a low cost growth method of high quality CdTe thin films. Although several reports on the application of electrochemically deposited $\mathrm{CdTe}$ films for photovoltaics ${ }^{3}$ and photoelectrochemical cells ${ }^{4-6}$ are available, the correlation between the deposition conditions and the composition and electronic properties of the films has not been well studied. This relation is very important in designing suitable materials for a given application. In this communication, the effect of the deposition potential on the composition $(\mathrm{Cd} / \mathrm{Te}$ ratio), type of the semiconductivity, and resistivity are reported.

$\mathrm{CdTe}$ films were deposited cathodically on Ti (The Japan Lamp Industrial Co. Ltd., $0.2 \mathrm{~mm}$ thick) or Ni sheets (The Japan Lamp Industrial Co. Ltd., $0.03 \mathrm{~mm}$ thick), which were degreased by a chloroform and an ethanol vapor and washed by deionized water before use, from an aqueous solution of $\mathrm{pH}=1.4$ containing $1 \mathrm{M} \mathrm{CdSO}_{4}$ and $1 \mathrm{mM} \mathrm{TeO}_{2}$ according to the method suggested by Panicker et al. ${ }^{7} \mathrm{~A}$ potentiostat (Hokuto Denko, HA-301) with a function generator (Hokuto Denko, HB-105) was used to control the electrode potential. The reagent grade $\mathrm{CdSO}_{4}$ (purity 99.5\%) and $\mathrm{TeO}_{2}$ (purity $99 \%$ ) were used as purchased. Water was purified by the Milli $Q$ water purification system. A usual three-electrode cell was used for the deposition of CdTe films. A platinum sheet and a $\mathrm{Ag} / \mathrm{AgCl}$ electrode were used as a counter and a reference electrode, respectively. The deposition of the films was carried out at room temperature after the electrolyte solutions were deaerated by passing a purified $\mathrm{He}$ gas through the solution for about $20 \mathrm{~min}$.

The type of semiconductivity of the deposited films was determined by measuring the potential difference between a

\footnotetext{
To whom correspondence should be addressed.
}

hot and cold contact. The sheet resistance of the films was determined by means of the four point probe technique. Xray diffraction and Auger electron spectroscopy (AES) measurements were carried out by using a Toshiba XC- $40 \mathrm{x}$-ray diffractometer and JEOL JAMP 10 S system $(10-\mathrm{keV}$ electrons), respectively.

$\mathrm{X}$-ray diffraction patterns of the films deposited at $-0.25,-0.35$, and $-0.60 \mathrm{~V}$ vs $\mathrm{Ag} / \mathrm{AgCl}$ are shown in Fig. 1. The diffraction peaks at $2 \theta=23.8,39.3$, and $46.4^{\circ}$ corresponding to (111), (220), and (311) face of CdTe, ${ }^{8}$ respectively, are observed and the formation of CdTe films is confirmed. The films deposited at potentials between -0.20 and $-0.65 \mathrm{~V}$ (vs Ag/AgCl) showed the peak due to $\mathrm{CdTe}$. The crystalline diameter of the deposited films is estimated to be less than $10 \mathrm{~nm}$ by using the Scherrer equation ${ }^{9}$ with the values of FWHM of the diffraction peak corresponding to (311). In addition to the diffraction peaks due to

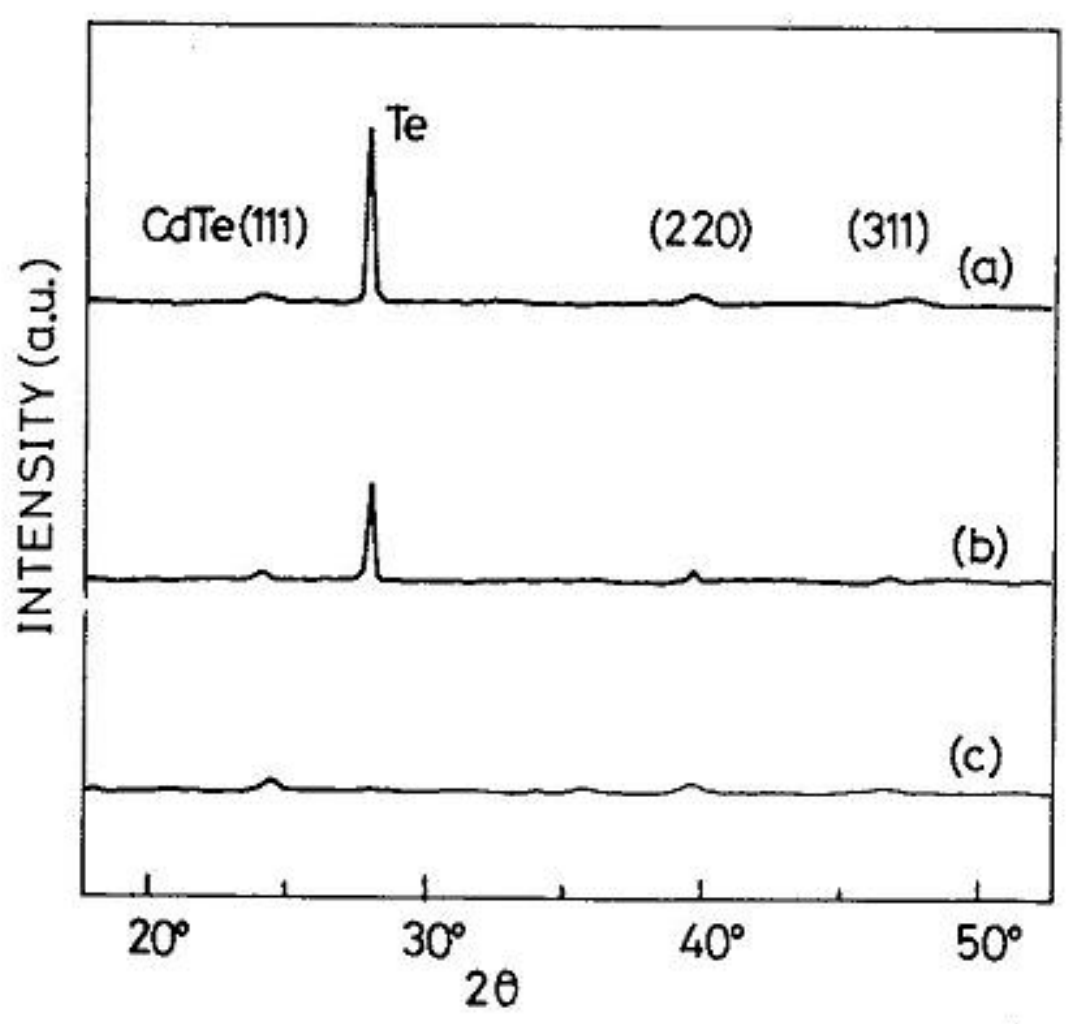

FIG. 1. X-ray diffraction patterns of electrochemically deposited CdTe films. Deposition potentials were (a) $-0.25 \mathrm{~V}$, (b) $-0.35 \mathrm{~V}$, (c) $-0.60 \mathrm{~V}$ (vs $\mathrm{Ag} / \mathrm{AgCl}$ ). 


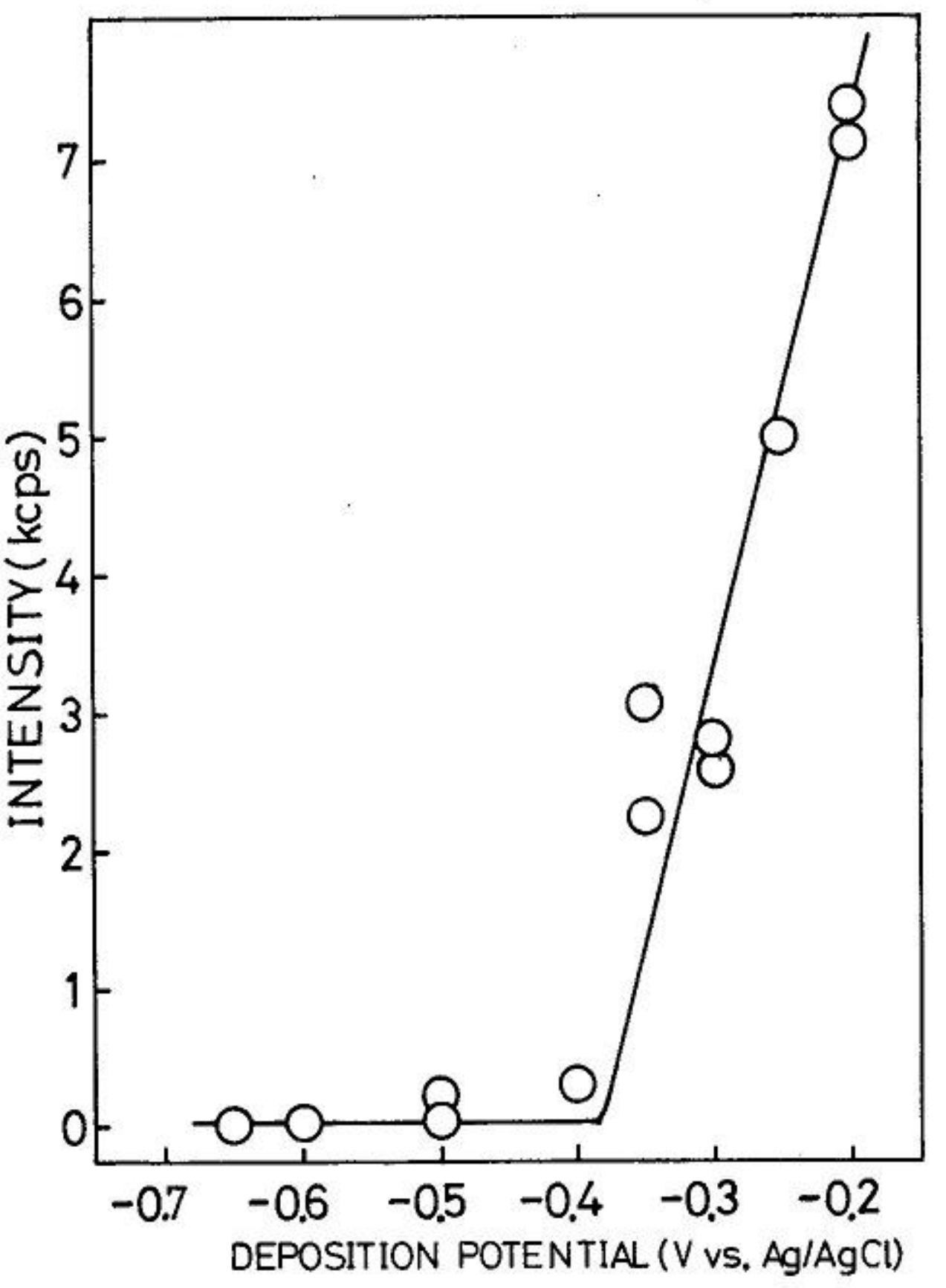

FIG. 2. Deposition potential dependence of the intensity of the x-ray diffraction peak due to $\mathrm{Te}$.

$\mathrm{CdTe}$, a diffraction peak was observed at $2 \theta=27.8^{\circ}$, which corresponds to Te metal. ${ }^{8}$ This peak is stronger for the films deposited at less negative potentials and is observed only for the films deposited at the potentials more positive than $-0.35 \mathrm{~V}$ vs $\mathrm{Ag} / \mathrm{AgCl}$, as shown in Fig. 2. The following electrochemical reactions are considered to be involved in the deposition process ${ }^{10}$ :

$$
\begin{aligned}
& \mathrm{HTeO}_{2}^{+}+3 \mathrm{H}^{+}+4 e^{-} \rightarrow \mathrm{Te}+2 \mathrm{H}_{2} \mathrm{O}, \\
& +0.342 \mathrm{~V} \text { vs } \mathrm{Ag} / \mathrm{AgCl}, \\
& \mathrm{Cd}^{++}+\mathrm{Te}+2 e^{-} \rightarrow \mathrm{CdTe} \\
& -0.155 \mathrm{~V} \text { vs } \mathrm{Ag} / \mathrm{AgCl} .
\end{aligned}
$$

At relatively positive potentials, Te metal is formed in the films by reaction (1) but reaction (2) is not sufficiently fast to consume all $\mathrm{Te}$ and, therefore, free $\mathrm{Te}$ was left in the films as an x-ray diffraction peak due to the excess free Te metal suggested. The more negative the deposition potential was, the faster reaction (2) was and the less free Te metal should be left. AES spectra of the films deposited at $-0.25,-0.35$, and $-0.60 \mathrm{~V}$ are shown in Fig. 3. Peaks due to Cd ( 375 and $382 \mathrm{eV})^{11}$ and Te $(481 \text { and } 491 \mathrm{eV})^{11}$ as well as those due to C $(325 \mathrm{eV})^{11}$ and $\mathrm{O}(517 \mathrm{eV})^{11}$ were observed. The $\mathrm{Cd} / \mathrm{Te}$ ratio is higher in the films deposited at more negative potentials. These results agree with those of $\mathrm{x}$-ray diffraction measurements. By $\mathrm{Ar}^{+}$sputtering, peaks due to $\mathrm{C}$ and $\mathrm{O}$ decreased significantly, as shown in Fig. 4, and the peaks due to $\mathrm{Te}$ shifted from 481 to $483 \mathrm{eV}$ and from 491 to $493 \mathrm{eV}$, respectively. These results suggest that contaminants such as $\mathrm{C}$ and $O$ existed mainly near the surface. The shift of the Te peak to

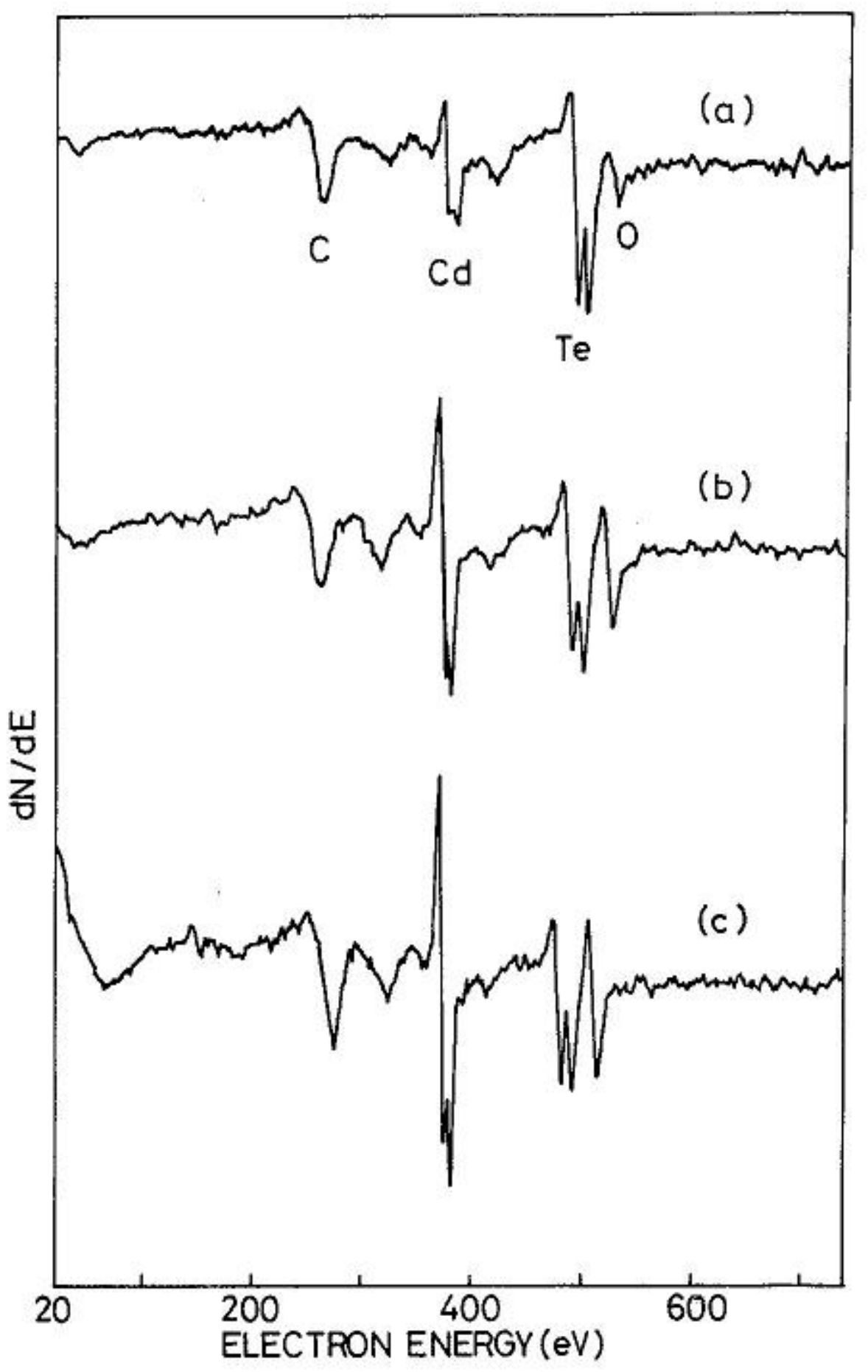

FIG. 3. Auger spectra of electrochemically deposited films. Spectra (a)-(c) correspond to the films cited in Fig. 1.

higher energy and the decrease of the $O$ peak by sputtering suggest that some of the $\mathrm{Te}$ at the surface existed as $\mathrm{TeO}_{2}$ which was confirmed by XPS measurements. ${ }^{12}$ It has been reported that the CdTe surface is easily oxidized in air and a $\mathrm{TeO}_{2}$ layer is formed. ${ }^{13}$

It is interesting to examine how the deposition potential, i.e., the composition of CdTe, correlates with the electronic properties of the CdTe films.

A "volcano" like relation between the deposition potential and the sheet resistance was observed as shown in Fig. 5. The types of semiconductivities of the films are also shown in Fig. 5. The films deposited at potentials more positive than $-350 \mathrm{mV}$ were $p$ type and those deposited at more negative potentials were $n$ type. For the films with $p$-type semiconductivity, the more negative the deposition potential was, the higher the resistance; for the films with $n$-type semiconductivity, the more positive the deposition potential was, the higher the resistance. These results can be explained as follows. It is known that $\mathrm{Te}$ vacancy and Cd vacancy act as a donor and acceptor, respectively; therefore, CdTe with a $\mathrm{Te}$ vacancy should be $n$ type and the one with a $\mathrm{Cd}$ vacancy should be $p$ type. ${ }^{2}$ Thus, the $\mathrm{Cd} / \mathrm{Te}$ ratio in the film strongly affects the type of semiconductivity. Since less $\mathrm{Te}$ is contained in the films deposited at more negative potentials, as discussed before, it is expected that the CdTe films deposited at relatively negative potentials are $n$ type and those deposited at relatively positive potentials are $p$ type. 
